\title{
Correction to: Assessing illegal fishing and trade of Atlantic billfsh and swordfsh by DNA-based identification
}

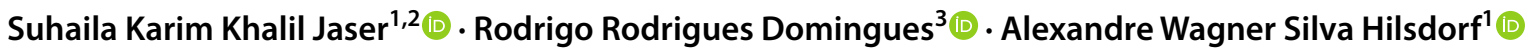

Accepted: 30 April 2021 / Published online: 8 May 2021

C) Springer Nature B.V. 2021

\section{Correction to:}

Conservation Genetics Resources (2021) 13:183-190 https://doi.org/10.1007/s12686-021-01190-y

Publisher's Note Springer Nature remains neutral with regard to jurisdictional claims in published maps and institutional affiliations.

The original version of this article, published on 21 st February, 2021, unfortunately contained a mistake in the body text citation, reference list and a missing citation.

The correct information is given below.

There was an error in body text citation and its citation in reference list "Mendonça et al. 2019" was removed.

An entry in reference list was missing. It should read as “: Ferrito V, Raffa A, Rossitto L, Federico C, Saccone S, Pappalardo, AM (2019) Swordfish or Shark Slice? A Rapid Response by COIBar-RFLP. Foods 8:537. https://doi.org/ 10.3390/foods8110537".

The original article can be found online at https://doi.org/10.1007/ s12686-021-01190-y.

Alexandre Wagner Silva Hilsdorf

wagner@umc.br

1 Núcleo Integrado de Biotecnologia, Universidade de Mogi das Cruzes, Av. Dr. Cândido Xavier de Almeida e Souza, 200, Mogi das Cruzes, SP 08780-911, Brasil

2 Universidade de São Paulo, Pós-Graduação Interunidades em Biotecnologia, Av. Prof. Lineu Prestes, 2415, ICB III, São Paulo, SP 05508-900, Brasil

3 Departamento de Ciências do Mar, Universidade Federal de São Paulo, Av. Dr. Carvalho de Mendonça, 144, Santos, SP 11070-100, Brasil 